\title{
Chronicle of the 1st International Animal Welfare Summit - Vienna, 24th April 2018
}

\author{
Martina Pluda
}

Head of Programmes, Four Paws/Vier Pfoten - Stiftung für Tierschutz Vienna, Austria

Recepction: June 2018

Acceptance: June 2018

\begin{abstract}
On April 24th, 2018 the international animal welfare organization FOUR PAWS hosted the 1st International Animal Welfare Summit in Vienna, Austria. The meta-question of the event: "Animal welfare - A Necessity for Human Survival or Only a Concern for the Privileged?”. More than 300 attendees took part in the event, to hear from over 20 highranking experts from the fields of science, agriculture, nutrition, economics, politics and arts. The core message, stressed by all speakers and participants, is that animal welfare is not just a niche topic, but a collective and existential issue.
\end{abstract}

Keywords: First International Animal Welfare Summit, animal welfare, human-animal coexistence, nutrition and production models, animal welfare as business opportunity

Resumen. Crónica de la 1a Cumbre Internacional de Bienestar Animal - Viena, 24 abril 2018.

El día 24 de abril de 2018, la organización internacional de bienestar animal FOUR PAWS acogió la $1^{\text {a }}$ Cumbre Internacional de Bienestar Animal en Viena, Austria. La pregunta objeto del evento fue la siguiente: "Bienestar Animal" - ¿Una necesidad para la supervivencia humana o solamente una preocupación para los privilegiados?” Más de 300 asistentes participaron en el evento para escuchar alrededor de 20 expertos de alto rango procedentes de campos de la ciencia, la agricultura, la nutrición, la economía, la política y el arte. El mensaje central, remarcado por todos los conferenciantes y participantes, es que el bienestar animal no es solo un tema de nicho, sino un problema colectivo y existencial.

Palabras clave: Primera cumbre internacional de Bienestar Animal, bienestar animal, coexistencia humano-animal, modelos de nutrición y producción, bienestar animal como oportunidad comercial 


\section{FOUR PAWS HOSTED THE $1^{\text {ST }}$ INTERNATIONAL ANIMAL WELFARE SUMMIT IN VIENNA, AUSTRIA}

On April 24th, 2018 the international animal welfare organization FOUR PAWS hosted the $1^{\text {st }}$ International Animal Welfare Summit (IAWS) in Vienna, Austria. The metaquestion of the event: “Animal welfare - A Necessity for Human Survival or Only a Concern for the Privileged?”. More than 300 attendees with a stake in animal welfare issues came from all corners of the world to take part in the event, that marks the 30th anniversary of FOUR PAWS, and to hear from over 20 high-ranking multidisciplinary experts from the fields of science, agriculture, nutrition, economics, politics and arts.

At the core of the conference was the message that animal welfare is not just a single issue, but one that is vital for our present and especially our future. The clearer we perceive the consequences of overpopulation, globalized agriculture, and irreversible environmental damage, the more we see economic, legal, and ethical issues becoming headline issues. The IAWS 2018 reflected this with a broad spectrum of contributions.

The morning sessions hosted prominent speakers and guests who gave interesting insights into their commitment for the animal cause. Whether politician, artist, journalist or activist, each speaker underlined the importance of animal welfare as a collective and existential issue. Animal welfare is now, more than ever, a legitimate concern, directly interconnected to the survival of our planet and the future of humanity.

The afternoon was then dedicated to three main topics that, as addressed in the morning sessions, clearly have crucial contact points with animal welfare: Habitats, Nutrition and Economy. The three panels explored the notions of human-animal co-existence, sustainability, and one welfare just to name a few. To view a recap of the summit, click here.

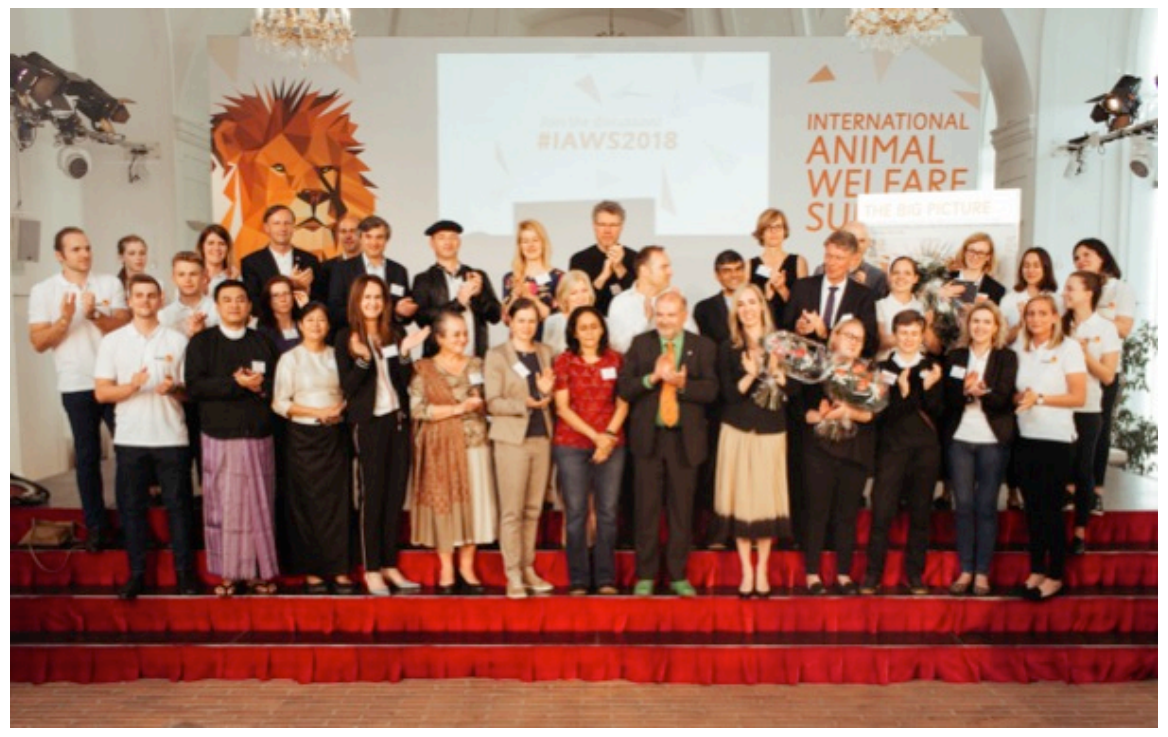

Picture 1: Speakers and team on stage for the final applause - (c) VIER PFOTEN | Adrian Almasan

\section{AUSTRIAN PRESIDENT ALEXANDER VAN DER BELLEN PATRON OF THE IAWS 2018}

The Austrian President of the Republic, Alexander Van der Bellen, took over the 
patronage of this unique summit, the first of its kind. In his opening speech, he spoke of animal welfare as a topic that is close to his heart. According to Van der Bellen, "Animal welfare is, thank goodness, no longer a niche topic”. Rather, "An existential question that concerns us all.” According to him the summit is a step in the right direction: "Today we will address important questions and try to find solutions together."

Now more than ever, we need to find universal solutions that take into account that global problems are no mere single issues, but rather the result of everything we do. "It's time we start looking at animal welfare as an integral part of society's progress, with farreaching implications for other areas”, Van der Bellen stated. To view an excerpt of the President's speech, click here.

Host Heli Dungler, founder and president of FOUR PAWS, addressed a bitter truth in his welcoming speech: Over the next 30-40 years, the number of farm animals on earth will double. In emergent countries in particular, meat consumption will increase dramatically. Dungler warned against the effects of this development not only on animals and their welfare, but also on the environment.

Many positive developments for animals have taken place in the past 30 years, since the founding of FOUR PAWS, but the work is not over. Many more challenges lay ahead and Dungler's objective for this event was to set the foundation for a new global debate.

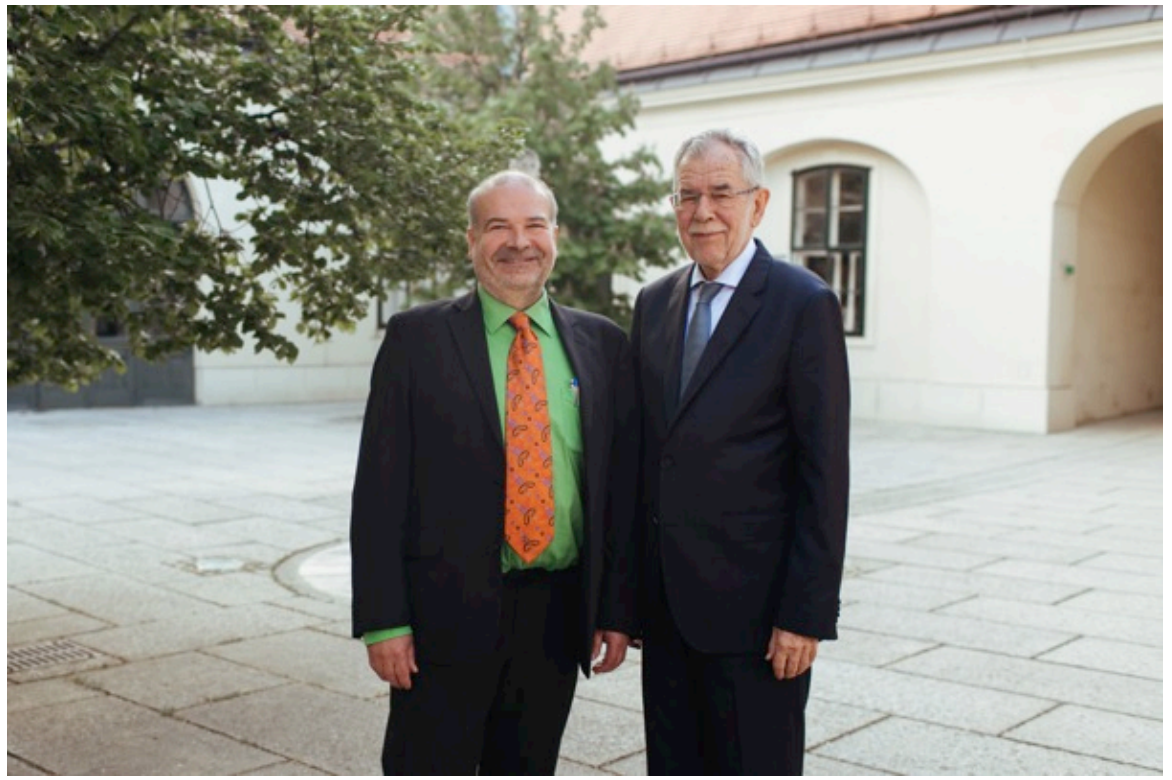

Picture 2: FOUR PAWS founder Heli Dungler with Austrian President Alexander Van der Bellen - (c) VIER PFOTEN | Adrian Almasan

The European Commissioner for Health and Food Safety, Vytenis Andriukaitis, also emphasized the importance of animal welfare: "We need to make ourselves aware that animals are sentient beings.” In his speech Andriukaitis spoke about the EU's recent achievements in animal welfare, but also on the huge challenges ahead. In the remaining months before the end of his term, the Lithuanian Commissioner specifically committed "to make as much progress as possible on the welfare of pigs and the implementation of legislation in EU Member States".

"Animal welfare is very important part of my responsibilities and indeed one of my personal priorities as Commissioner for Health and Food Safety. We should not take our foot 
off the pedal, and slow down activities in the field of animal welfare. There are still many issues to be solved and we need to continue to have a proactive EU policy on animal welfare" he stated.

Andriukaitis also referred to the Eurobarometer survey, which indicates that an absolute majority of Europeans considers the protection of animal welfare very important and would like to see improvements in the way the welfare of animals is protected. That is one of the reasons why, "We launched the EU Platform on Animal Welfare which aims to promote dialogue among competent authorities, businesses, civil society and scientists on animal welfare issues that are relevant for EU citizens", he stated. "To get concrete results, mutual understanding and trust between all players as well as concrete engagement by each actor is an essential first step and it is one of the key objectives of the Platform”, he concluded.

A reply to the Commissioner's statement came from Reineke Hameleers, Director of the Eurogroup for Animals. According to her the political dynamics have changed enormously in the past few years so, "We need to demonstrate strong civil society support, linked to corporate engagement”. For Hameleers it is clear that the joint action of citizens and businesses can lead to institutional change.

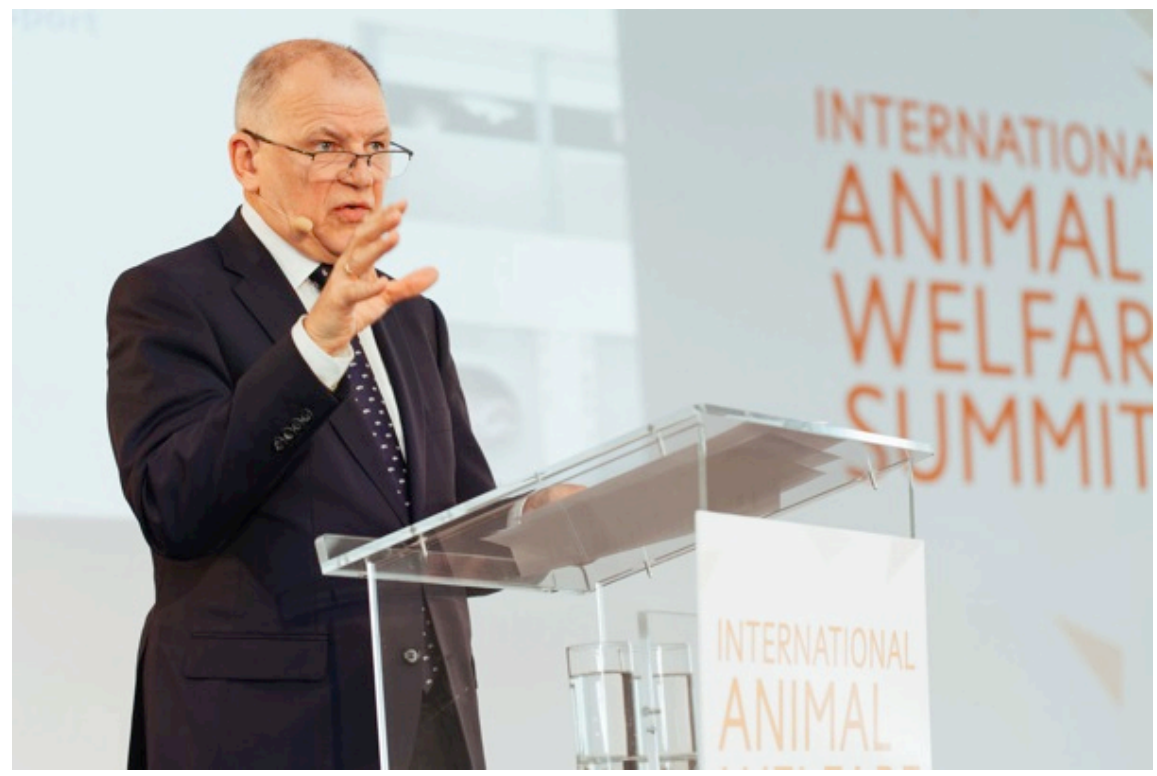

Picture 3: European Commissioner for Health and Food Safety, Vytenis Andriukaitis - (c) VIER PFOTEN | Adrian Almasan

\section{SPECIAL GUEST AI WEIWEI, CHINA'S MOST RENOWNED CONTEMPORARY ARTIST, AT THE SUMMIT: “ANIMALS HAVE BEEN VICTIMS OF HUMANS FOR FAR TOO LONG”}

The highlight of the summit was the special appearance of Chinese conceptual artist and human rights activist Ai Weiwei. He is renowned for making strong aesthetic statements that resonate with timely phenomena across today's geopolitical world. From architecture to installations, social media to documentaries, Weiwei uses a wide range of mediums as expressions of new ways for his audiences to examine society and its values.

In his eagerly awaited interview on stage, Weiwei explained his personal connection 
with FOUR PAWS which was established a few years ago when he was documenting the situation of refugees in Gaza for his acclaimed film "Human Flow". There he came across a tiger, trapped in an abandoned zoo, later rescued by FOUR PAWS and rehomed in the organization's big cat sanctuary LIONSROCK, in South Africa.

Animals, according to Ai Weiwei, have always been part of human life and, at the same time, have been victims of humans for far too long. "It's time to reflect on human values and show more responsibility towards all living creatures”, he added. The animal condition is inevitably connected to the human condition and we need to support the idea that all lives are created equally. To view an excerpt of Ai Weiwie's speech, click here.

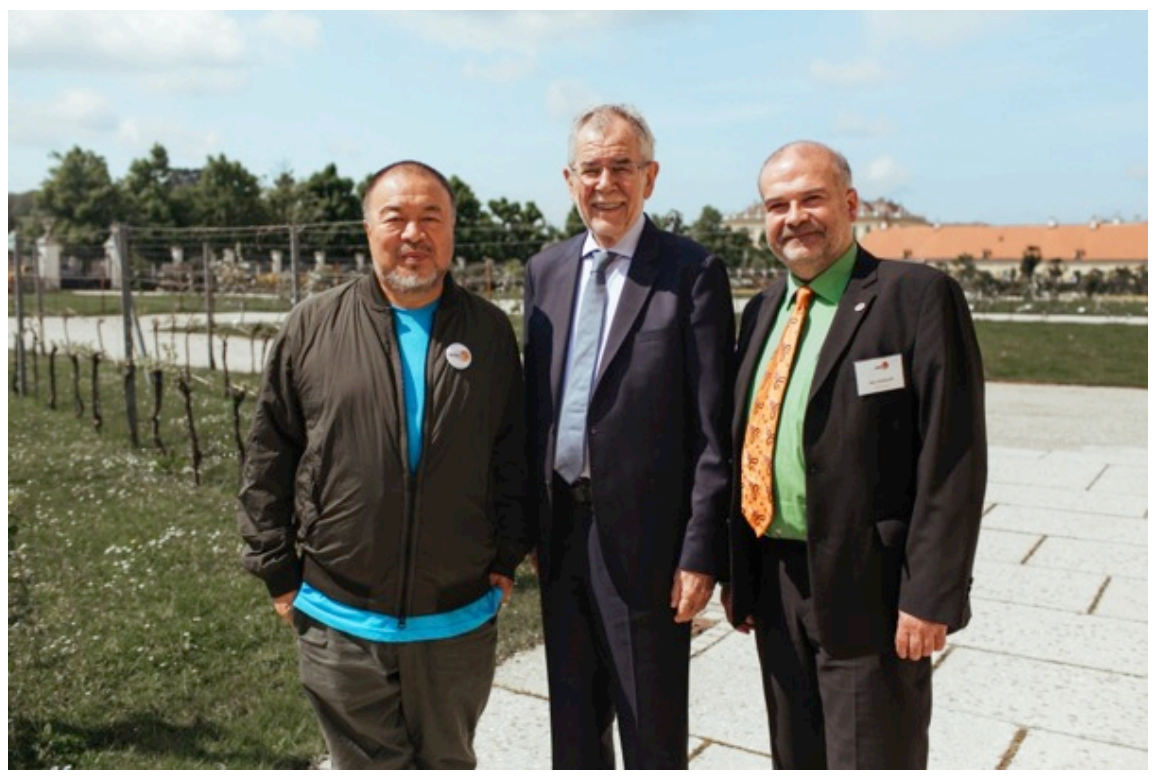

Picture 4: Chinese artist Ai Wiewei, Austrian President Alexander Van der Bellen, and FOUR PAWS founder and Heli Dungler - (c) VIER PFOTEN | Adrian Almasan

\section{KEYNOTE SPEAKER RAJ PATEL: “WE ARE ALL PART OF THE WEB OF LIFE”}

Award-winning writer, activist and academic Raj Patel followed with his keynote, “A Planet for All?”. In his lively and eye-opening talk, he focused on cheap mass production with all its devastating effects on humans, animals, and the environment because, "It isn't just about them, it isn't just about us, it's about the larger community of us together" Patel stated.

According to Patel, through terms like "the Anthropocene”, we are told that today's ecological catastrophe is an inevitable consequence of being human. This is incorrect, but there's good and bad news. The bad news first: we are undoubtedly in the middle of a profound socio-ecological state-shift. The twenty-first century will be dramatically different from any that preceded it, and our elected representatives and the business community shows little capacity to comprehend the scale of shifts necessary for life on Earth to thrive in the years ahead. But the Anthropocene era, the geological epoch through which we live, and which will be written in the fossil record with markers such as oceanic plastic, atmospheric radiation, and chicken bones, is not the inevitable product of being human. This is good news.

Our fate is not written into our species. Our current trajectory of state-shift comes from a social-ecological system that, among other things, has a central idea: that humans are 
separate from nature, and from animal life. Few civilizations have made this mistake, which is why no other civilization has approached our level of systemic damage. What, then, might it be like for us to renegotiate relationships between humans and other beings in the web of life? In his talk, Patel presented a history of our current predicament, and suggested some hard questions that we will need to answer if we are to imagine a survivable planet in which our relationships with animals and the web-of-life allows us all to survive, and thrive. To view an excerpt of Raj Patel's speech, click here.

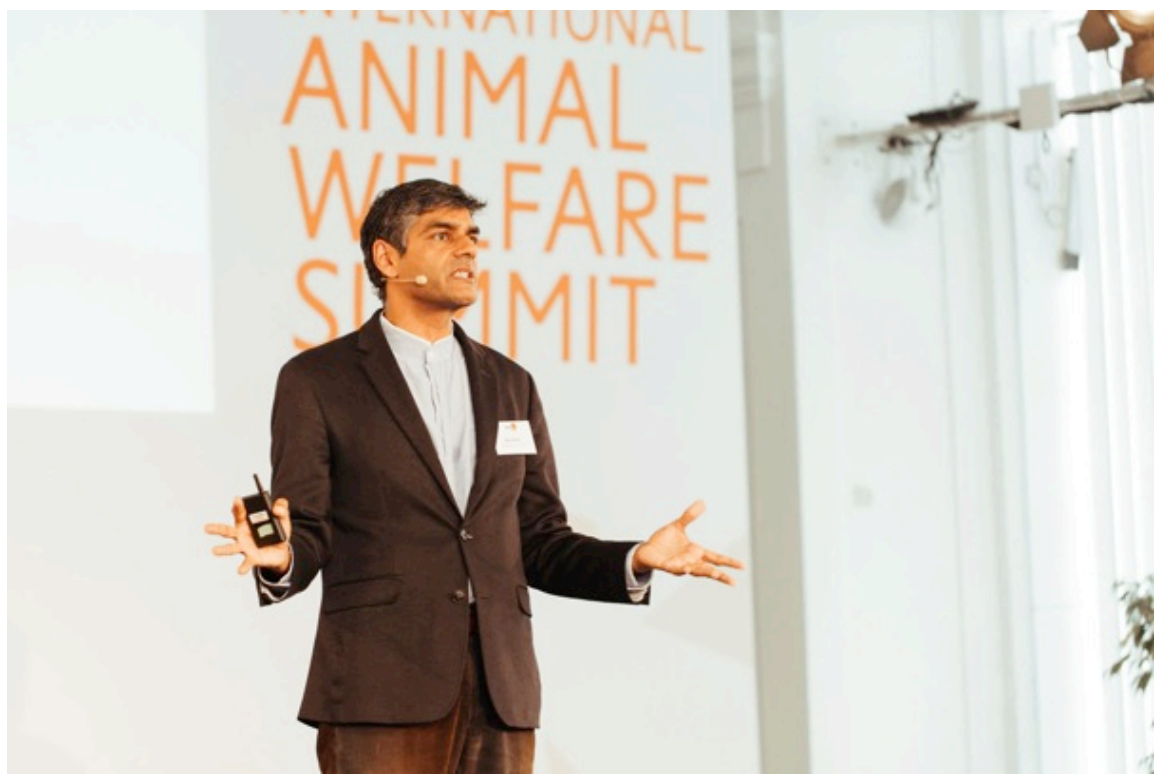

Picture 4: keynote speaker Raj Patel - (c) VIER PFOTEN | Adrian Almasan

\section{SPECIAL AMBASSADORS FOR A SPECIAL TASK}

Still in the morning session, both Her Royal Highness Princess Alia Al Hussein of Jordan, founder of the "Princess Alia Foundation" and long friend of FOUR PAWS, as well as the renowned Austrian animal activist and journalist Maggie Entenfellner, were appointed special ambassadors of the IAWS. With their strong commitment and incredible engagement, they will seek to enhance public understanding for the vision and goals of the International Animal Welfare Summit and help focus attention on the essential work of animal welfare groups.

"Everything is linked”, HRH Princess Alia of Jordan stated. "It is important for us all to approach these topics in a holistic way. It's not only about the welfare of the animals and the planet, but also about our humanity as human beings”.

The IAWS is a completely new approach, especially because a wide range of thinkers contributed with their own, field-specific views on animal welfare. For the animal cause this is a step into the future. As FOUR PAWS founder Heli Dungler explained, "Nowadays, we must look at animal welfare from all different angles, drawing stakeholders together to get a balanced view of the big picture. For this challenging but necessary task we need engaged personalities, who can help to spread awareness”.

To view an excerpt of the ambassadors' appointment and intervention, click here. 


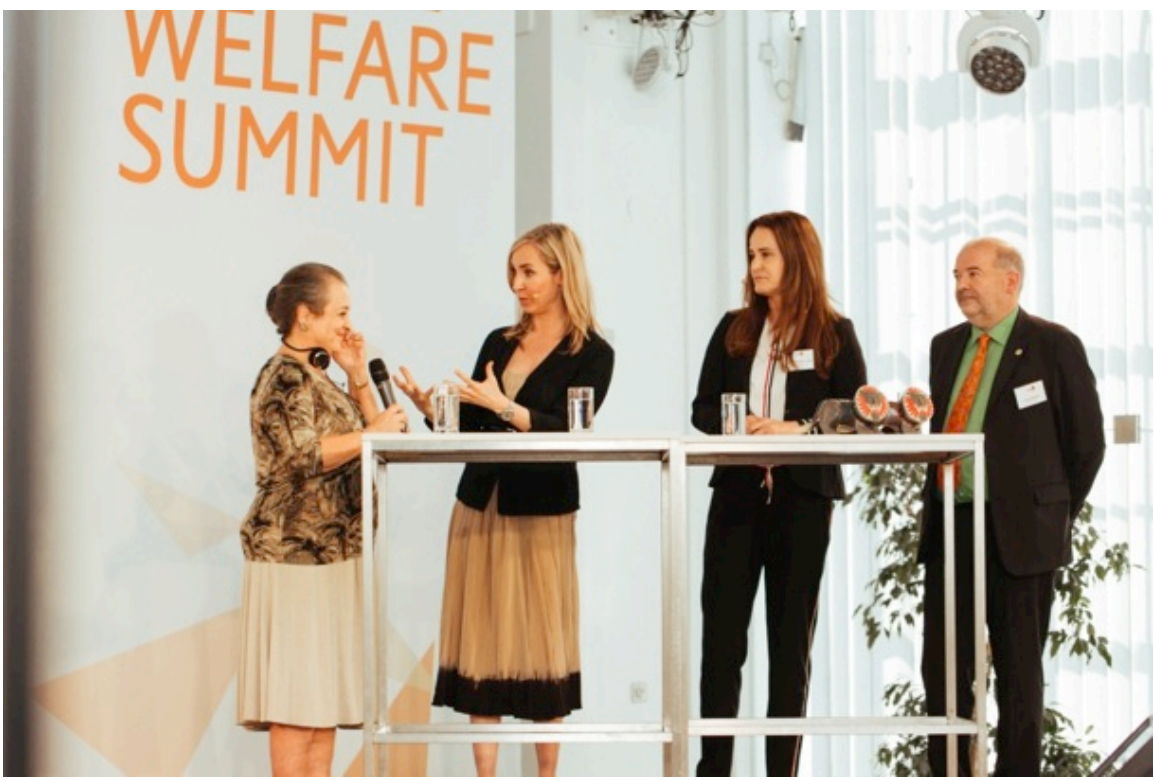

Picture 5: HRH Princess Alia of Jordan, Austrian journalist Maggie Entenfellner with presenter Nadja Bernhard and FOUR PAWS founder Heli Dungler - (c) VIER PFOTEN | Adrian Almasan

\section{PANEL HABITATS: SURVIVAL OF THE FITTEST - A PLANET ON THE EDGE?}

The fact that humans and animals share the same living space fundamentally impacts their relationship in many ways. How much space is each species entitled to and how do we want to shape our coexistence in the same biosphere? Historically humans have conquered their living space, pushing and confining other species in the process. By now, that process has reached the critical point called the sixth mass extinction.

According to filmmaker and author Marc Pierschel, the loss of habitat is threatening many species and conflicts arising from introducing invasive predators has created often irreversible problems. In cities, rodents and other animals that have found their own niche are often seen as pests. Yet, the urban population is longing for closer relationships with animals which is testament to a growing population of companion animals. So how we transform our cities, our infrastructure and our environment so that we meet the needs and interests of animals that are affected by our actions? For Pierschel, "The Zoopolis, is the vision for a human and animal community so that we can coexist peacefully". To view an excerpt from Pierschel's speech, click here.

In his talk Paul Waldau, professor and author, maintained that, "When human individuals act as responsible members of the more-than-human Earth community (through, for example, employing a robust sense of "animal welfare"), such a way of life fosters the well-being of each human community and its individuals." According to Waldau such an achievement contrasts markedly with the harms done to nonhumans, as well as those done to humans, by today's dominant narrative of human exceptionalism. "This dysfunctional form of human-centeredness has produced the cruelties and indifference that prevail in modern economies, agribusiness, national research establishments, law, education and religious institutions. The good news is that our efforts today can build on much work that today envisions a more responsible form of human citizenship in the multi-species Earth 
community” concluded Waldau. To view an excerpt from Waldau's speech, click here.

On the topic of co-existence, an interesting example came from India, a country with one of the highest densities of humans and livestock, but also the highest populations of many highly endangered wildlife species. Vidya Athreya, ecologist who has been working on the human leopard conflict issue for 15 years, explained how different interests on the same patch of land can be reconciled: "Our work shows that there are various kinds of relationships between people and large wildlife in India, often cloaked under the singular term of "conflict". They key is to change people's fear into understanding". To view an excerpt from Athreya’s speech, click here.

Particularly interesting was the fishbowl discussion with HRH Princess Alia of Jordan, journalist Corinna Milborn, Marcus Bachmann from Doctors Without Borders and Phone Win, founder of the NGO Mingalar Myanmar on a very particular matter: “Crises, wars, catastrophes - do animals have a right to rescue?” Here the topics of ethical reasons of intervening to help animals in humanitarian crises and on co-existence intended as solidarity interspecies were explored.

\section{PANEL NUTRITION: "MEATING" THE DEMAND OF A GROWING POPULATION?}

Here the discussion focused on the future of nutrition and alternative models: Meat or no meat? Animal, insect, plant-based, or lab grown proteins? The race for possible future sources of nutrition and production models is well underway. The aim of it all is to solve stark problems on several levels, in particular how to produce enough food for an evergrowing population, while at the same time cutting the use of resources and the suffering of farm animals. For Jörg Luy, veterinarian and expert in animal ethics, to eat or not to eat animals, is perhaps the most important ethical question, "because the ecological future of mankind is at stake”.

Journalist and author Tanja Busse stated clearly, "We cannot continue to eat the way we eat. Our food system needs a change very urgently. The way we produce and consume food in the Western world is harming our health, the environment, farmers and also animals - both livestock and wildlife. It is extremely important for all the progressive powers to work together and to develop a common vision of a better food system and farmers need to be part of the solution. Slightly higher animal welfare standards within a thoroughly unsustainable food system is not an option”. To view an excerpt from Busse's speech, click here.

For Guillaume Betton, of the Pôle Viandes Locales, an initiative of 60 members that combines all steps of production "from field to plate", it is of utmost importance to keep in consideration the animals' needs: they don't see, smell or hear like us. The way animals perceive the environment is completely different and models that do not take this fact into account, cause unnecessary stress and suffering. Betton's model, on the contrary, does not only mean entrepreneurial freedom for the farmers, but animal welfare from birth to death. "Entirely free from the dictates of industrial factory farming, the animals can experience a slow and healthy life cycle” Betton explained. To view an excerpt from Betton's speech, click here.

According to Tarique Arsiwalla, Vice President of the International Platform of Insects for Food and Feed, insects can bring our food production system to a more preferred level of sustainability while addressing animal welfare. "Reducing meat consumption would have the biggest impact in solving animal welfare issues. However, by moving from for example red meat to eating insects we believe a significant step could also be made in both footprint and animal welfare improvement in animal farming”, he explained. "And yes, insects are also animals but they do not have a nervous system. Can they therefore feel pain and discomfort? The truth is: We do not know yet”. Nevertheless, for Arsiwalla it is clear 
that Brambell's five freedoms must be considered when farming them. To view an excerpt from Arsiwalla's speech, click here.

Kurt Schmidinger, food scientist and founder of the project Future Food, gave some insights on the trending topic of cultured meat or "clean meat". With consistent investments from prominent personalities such as Leonardo Di Caprio and Bill Gates, the front-runners include American firm Memphis Meats, as well as the Mosa Meat company founded by the Dutch scientist Mark Post, who unveiled the first in-vitro burger in 2013. For Schmidinger there is no question that clean meat will revolutionise the market but its success depends on two key factors: whether it will be able to compete on price and whether taste, appearance, and consistency will be good enough to overshadow people's prejudice for food grown in laboratories. Schmidinger appealed to the sceptics, "The manufacturing process is not unlike a brewery. Yet we do not call beer 'lab-beer' and give it a negative connotation.” To view an excerpt from Schmidinger's speech, click here.

\section{PANEL ECONOMY: ANIMAL WELFARE - ADDED VALUE OR PASSING TREND?}

This panel touched on the business-related aspects of animal welfare, both from the corporate and the consumer perspective; it explored the risks and opportunities for companies who decide to invest in animal welfare and what motivates consumers to buy these products. Consumers and businesses have learned a few economic lessons in recent decades, setting many new standards along the way. However, it remains unclear whether our improved understanding will be enough to mitigate the impact of affluent consumption, or whether it is just a matter of new market niches to serve the critical mass. To this extent this panel brought exciting examples, but also showed the tension between animal welfare, sustainability and ethics on the one hand and profitability on the other.

From a business viewpoint, the unavoidable questions are whether animal welfare measures will represent a competitive advantage. According to Nicky Amos, Executive Director Business Benchmark on Farm Animal Welfare, "Despite the progress seen in recent years on corporate management of farm animal welfare, the reality is that companies continue to face structural and commercial barriers to making farm animal welfare an integral part of their business strategy”. The most commonly identified barriers are a perceived lack of customer willingness to pay for higher farm animal welfare, the capital investment required to deliver higher standards of farm animal welfare, and a general lack of awareness of the wider business and marketing benefits of higher welfare. To view an excerpt from Amos' speech, click here.

Amongst consumers a growing awareness of production conditions is noticeable, leading to the demand for higher standards as well as more transparency. With a practical example, veterinarian Jörg Altemeier, Head of Animal Welfare at Tönnies Lebensmittel, explained why one of the biggest slaughterhouses for cattle and pigs in Germany decided to implement higher animal welfare standards, and how it seeks to positively influence the previous steps in the production chain, such as transport. To view an excerpt from Altemeier's speech, click here.

One more example was presented by Pamela Ravasio, Head of CSR \& Sustainability at European Outdoor Group and Hanna Denes, Senior Standards Manager at Textile Exchange, who illustrated how efforts around animal welfare in supply chains of the outdoor industry opened the door to a complex multidimensional puzzle. One where animal welfare is but a single component. Ravasio explained that, "The outdoor industry has been working on animal welfare for many years. We have evolved from having very little knowledge on species specific requirements to being progressively educated on the needs of those animals we touch in our supply chains". Yet, precisely due to the intention to do the right thing, outdoor businesses have come across every challenge imaginable to 
balance requirements of different types: commercial, performance, animal welfare, environment, social and labour demands, time to market, logistics, production costs, local regulation and law enforcement to name a few.

Finally, motive researcher Helene Karmasin explored the consumer's viewpoint. She maintained that animal welfare would be easy to enforce if consumers actively favoured those goods that take this aspect into account, even if they had to pay a little more for it. According to Karmasin though, "the consumer" does not exist: "Indeed, there are many different groups of consumers who differ by socio-demographics, values, moral orientations, and lifestyles". As with anything traded on a market, communication strategies play an important role: How is trust built? How are people convinced to buy a specific product? Even highly moral goods cannot rely on the rational discourse alone, but must consider the motivations and attitudes of each consumer group. To view an excerpt from Karmasin's speech, click here. 